\section{St. Louis Enzephalitis-Viren (SLEV)}

W. Stöcker

Euroimmun Medizinische Labordiagnostika AG, Lübeck, Deutschland

Englischer Begriff St. Louis encephalitis virus

Beschreibung des Erregers Familie: Flaviviridae; Gattung: Flavivirus; Art: St. Louis Enzephalitis-Virus. PlusstrangRNA-Genom, ca. $40 \mathrm{~nm}$ Durchmesser.

Erkrankungen Vorkommen: Nordamerika, Karibik, Mittelund Südamerika.

Vektoren: Stechmücken (verschiedene Culex-Spezies).

Wirte: Vögel (Virusreservoir), Menschen (Endwirt).

Klinik: Über $99 \%$ der Patienten zeigen keine oder nur leichte Symptome. Kommt es zu einer Meningoenzephalitis (häufiger bei älteren Patienten) oder Enzephalitis, treten zunächst Fieber, Kopfschmerzen, Nackensteifigkeit, Verwirrung, Schläfrigkeit auf. Im späteren Verlauf kann es zu Tremor, Spontannystagmus, Myoklonien, Rigor, Paralysen, Ataxie bis hin zum Koma kommen. Weitere Komplikationen: Bronchopneumonie, gastrointestinale Blutungen. Die Letalitätsrate liegt bei jungen Patienten unter $5 \%$, steigt aber altersabhängig auf bis zu $15 \%$. Neuropsychiatrische Spätfolgen, wie Müdigkeit, Vergesslichkeit, Konzentrationsstörungen sind möglich.

Analytik Direktnachweis: Nachweis viraler RNA durch RT-PCR (Polymerase-Kettenreaktion), Virusanzucht.

Serologie: Nachweis spezifischer Antikörper (IgM, IgG) im Serum durch z. B. indirekte Immunfluoreszenz, $\checkmark$ Enzyme-linked Immunosorbent Assay.
Probenmaterial Direktnachweis: Blutplasma, Liquor oder Gewebe. Das Material sollte bis zur Weiterverarbeitung bei +4 bis $+8{ }^{\circ} \mathrm{C}$ aufbewahrt werden.

Serologie: Serum oder Plasma für den Nachweis der Antikörper sind bei $+4{ }^{\circ} \mathrm{C}$ bis zu 2 Wochen lang beständig, bei $-20{ }^{\circ} \mathrm{C}$ über Monate und Jahre hinweg. Zur Tiefkühlkonservierung des IgM kann man den Proben 80 \% gepuffertes Glyzerin beifügen.

Diagnostische Wertigkeit In den USA zählen die SLEV zu den häufigsten Auslösern viraler Enzephalitis-Epidemien. Direktnachweise des Virus kurz nach der Infektion sind zwar möglich, aber schwierig. Der Nachweis spezifischer IgM-Antikörper ist etwa ab dem 3.-5. Krankheitstag möglich, zu beachten sind Kreuzreaktionen mit Antikörpern gegen andere Flaviviren (FSME-, Gelbfieber-, Dengue-, West-Nil-, Zika-, Powassan-Viren, u. a.). Ein vierfacher Anstieg des spezifischen Antikörpertiters in einer zweiten Serumprobe gilt als eindeutiger Nachweis der Infektion.

Differenzialdiagnose: West-Nil-Fieber, andere bakterielle oder virale ZNS-Infektionen mit Meningitis oder Enzephalitis.

\section{Literatur}

Center for Disease Control and Prevention (2010) Saint Louis encephalitis, Atlanta, 29 Jan. https://www.cdc.gov/sle/index.html. Zugegriffen am 02.08.2017

Robert-Koch-Institut, Berlin (2011) Steckbriefe seltener und importierter Infektionskrankheiten. Robert-Koch-Institut, Berlin 